\title{
Targeting VEGF in canine oxygen-induced retinopathy - a model for human retinopathy of prematurity
}

This article was published in the following Dove Press journal:

Eye and Brain

20 May 2016

Number of times this article has been viewed

\section{Scott McLeod \\ Gerard A Lutty}

Department of Ophthalmology, Wilmer Ophthalmological Institute, Johns Hopkins Hospital, Baltimore, MD, USA
Correspondence: Gerard A Lutty Department of Ophthalmology, Wilmer Ophthalmological Institute, Johns Hopkins Hospital, M04I Smith Building, 400 North Broadway, Baltimore, MD 21287 , USA

Tel + I 4I09556750

Fax + I 4109553447

Email glutty@jhmi.edu

\begin{abstract}
Development of the dog superficial retinal vasculature is similar to the mechanism of human retinal vasculature development; they both develop by vasculogenesis, differentiation, and assembly of vascular precursors called angioblasts. Canine oxygen-induced retinopathy (OIR) was first developed by Arnall Patz in an effort to experimentally determine the effects of hyperoxia on the development of the retinal vasculature. The canine OIR model has many characteristics in common with human retinopathy of prematurity. Exposure of 1-day-old dogs to hyperoxia for 4 days causes a vaso-obliteration throughout the retina. Vasoproliferation, after the animals have returned to room air, is robust. The initial small preretinal neovascular formations anastomose to form large preretinal membranes that eventually cause tractional retinal folds. The end-stage pathology of the canine model is similar to stage IV human retinopathy of prematurity. Therefore, canine OIR is an excellent forum to evaluate the response to drugs targeting VEGF and its receptors. Evaluation of an antibody to VEGF-R2 and the VEGF-Trap demonstrated that doses should be titered down so that preretinal neovascularization is inhibited but retinal revascularization is able to proceed, vascularizing peripheral retina and preventing it from being a source of VEGF.
\end{abstract}

Keywords: angioblasts, blood vessels, endothelial cells, oxygen, retinopathy, retina, vascular endothelial cell growth factor

\section{Introduction}

Human retinopathy of prematurity (ROP) results when the developing retinal vasculature in the premature infant is exposed to higher-than normal oxygen levels (hyperoxia). Hyperoxia causes development of the retinal vasculature to cease and vaso-obliteration to occur. As the neural retina continues to develop and consumes greater levels of oxygen, the retina becomes hypoxic due to an attenuated retinal vasculature. The resultant hypoxia causes increased levels of hypoxia inducible factor (HIF) and subsequent increased expression of HIF-inducible angiogenic factors like VEGF cause the vasoproliferative stage in ROP. Oxygen-induced retinopathies (OIRs) are animal models for human ROP. None of the models exactly replicates human ROP, but each has some pathological characteristics that mimic the human disease. Canine OIR was first developed by Arnall Patz in an effort to experimentally determine the effects of hyperoxia on the developing retinal vasculature ${ }^{1,2}$ and modified by Flower et al. ${ }^{3}$ Dogs are similar to humans in regards to the mechanism of retinal vascular development, and also the end-stage pathology of the canine model is similar to stage IV human ROP having tractional retinal folds in retina. 


\section{Canine retinal vasculature forms by vasculogenesis}

Unlike rodents, the superficial retinal vasculature of the dog develops by vasculogenesis and not angiogenesis. Vasculogenesis is the development of blood vessels by differentiation, aggregation, and assembly of vascular precursors or angioblasts (Figure 1). This process is occurring at birth in dogs and begins in humans at around 14 weeks gestation. ${ }^{4-6}$ The canine retina is only $60 \%$ vascularized at

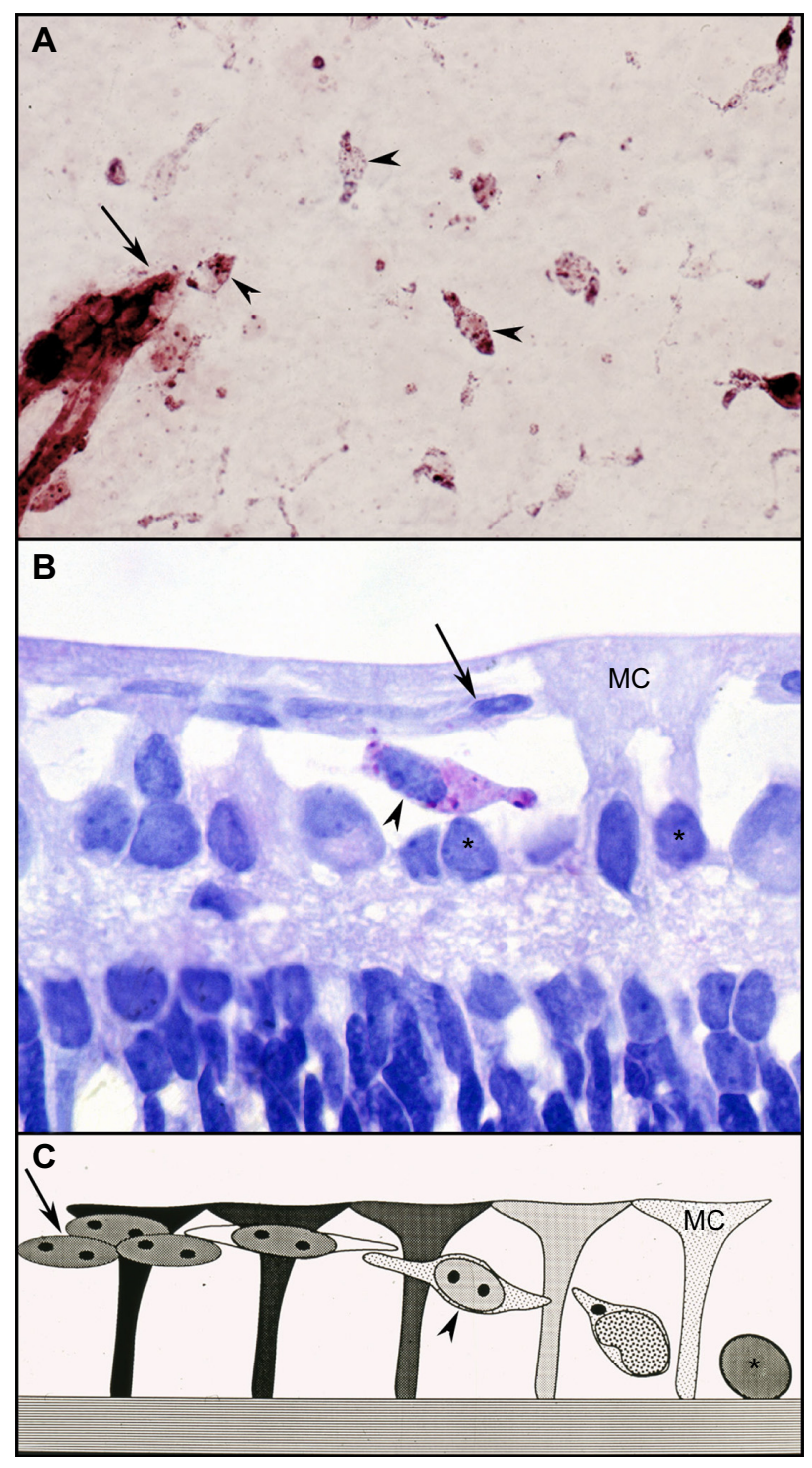

Figure I Vasculogenesis in the newborn dog.

Notes: (A) ADPase flat mount showing vascular cords at the edge of developing vasculature (arrow) and angioblasts in a vascular periphery (arrowheads). (B) JB-4 section of ADPase flat-embedded I-day-old dog retina at the edge of developing vasculature shows a vascular cord (arrow), Muller cell processes (MC), and a differentiating angioblast migrating within the cell-free spaces (arrowhead). Undifferentiated angioblasts are shown below the forming vascular cords (asterisks). (C) Schematic of angioblast differentiation in cell-free spaces made by MC: arrow, vascular cord; arrowhead, differentiating angioblast; asterisk, undifferentiated angioblast.

Abbreviation: ADPase, adenosine diphosphatase. birth and angioblasts (positive for adenosine diphosphatase [ADPase] enzyme activity) are present throughout avascular peripheral retina at this time. ${ }^{4,7}$ The initial assembly of the angioblasts results in cords and then lumen develop within the cords. In dogs and humans, astrocyte (the inner retinal glia) differentiation trails vascular development and guidance is provided by Muller glia not astrocytes, unlike neonatal rodent retinas. ${ }^{5-7}$ The Muller cells, which span the retina from internal to external limiting membrane, form glycosaminoglycan-rich extracellular spaces in which vasculogenesis occurs ${ }^{4}$ while also providing adenosine via the enzyme $5^{\prime}$ nucleotidase to stimulate the vasculogenic process. $^{7}$ Vascular endothelial cell markers (CD34 and von Willebrand's factor) are not expressed in angioblasts and are expressed only in endothelial cells after lumen formation and presumably the presence of serum within the lumens.

\section{Canine model of oxygen-induced retinopathy}

Newborn dogs are placed into 100\% oxygen for 4 days to induce retinopathy. This exposure to hyperoxia arrests the development of the superficial retinal vasculature and causes the vaso-obliterative phase of OIR (Figure 2). This results in $60 \%$ loss in vascular area and the vaso-obliteration is the greatest in the capillaries, whereas large blood vessels appear viable as determined by ADPase activity (Figure 3 ). ${ }^{8}$ The vasoobliteration occurs throughout the retina but islands of surviving endothelial cells can be found throughout the once-vascularized areas (Figure 3). The loss of vasculature in the presence of a differentiating neuroblastic layer (neuronal progenitors) after removal from hyperoxia results in extreme hypoxia, the initiating event in the vaso-proliferative stage in canine OIR.

Revascularization of retina occurs in a burst of disorganized angiogenesis that results in a very dense capillary network in the inner retina (Figure 4). ${ }^{9}$ The extracellular spaces created by Muller cell processes are filled with proliferating astrocytes, and multiple layers of capillaries form the inner retina. At the periphery of the surviving retinal vasculature, glial proliferation occurs resulting in gliosis; in humans, gliosis causes the formation of a ridge of tissue between vascularized and nonvascularized retina, but no anatomical ridge occurs in dogs. ${ }^{10}$ By postnatal day 15 (P15), tufts of neovascularization can be seen in vitreous with fundus and red free photography (Figure 5). ${ }^{9}$ Vitreous, the gel in posterior chamber of the eye, normally has had regression of the fetal vasculature occur by this time and is becoming avascular. Fluorescein angiography demonstrates the leaky nature of these formations and the extreme tortuosity of arteries (Figure 5). ${ }^{11}$ In cross sections, 

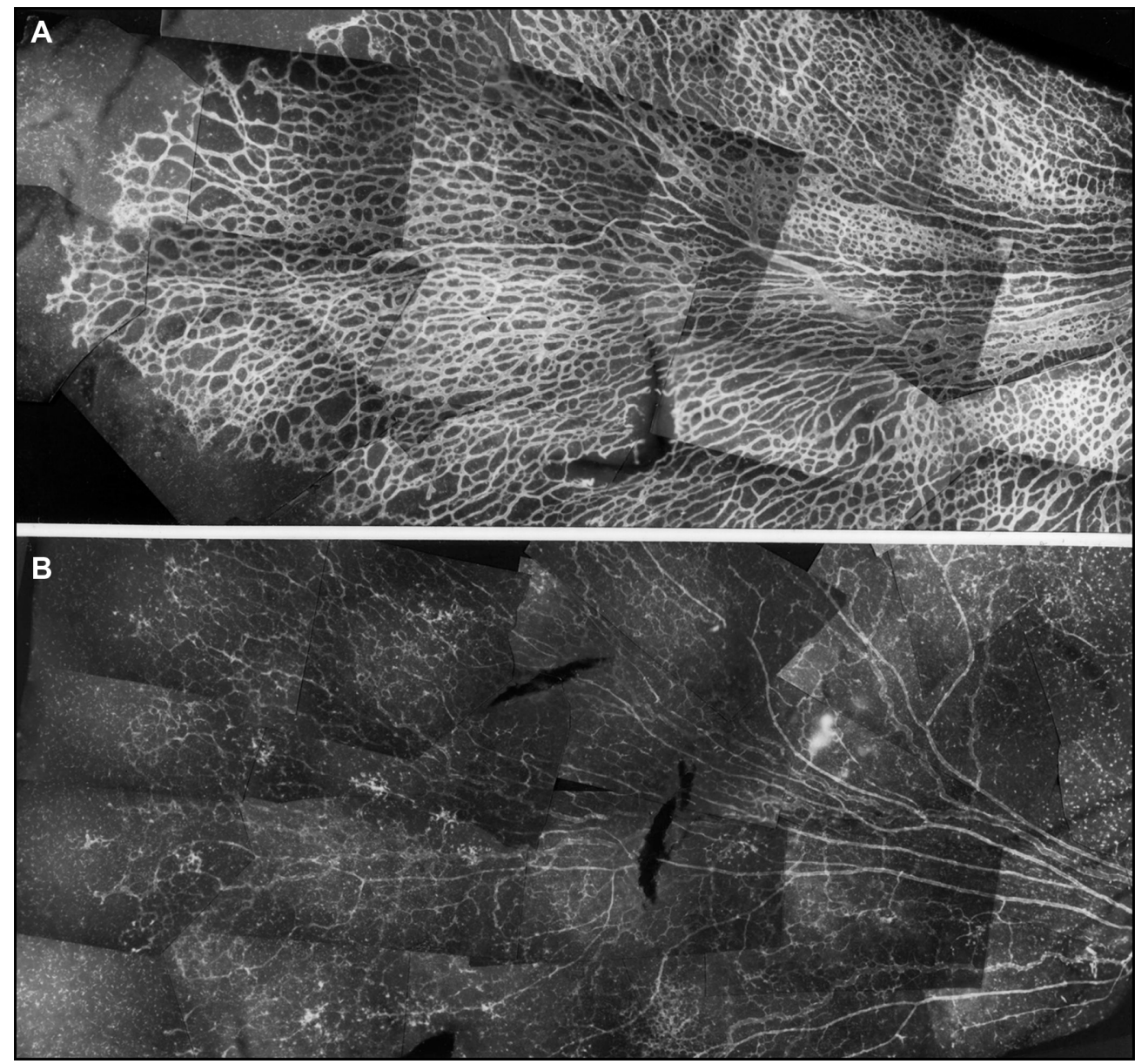

Figure 2 Vaso-obliteration in the dog model of OIR.

Notes: ADPase flat-embedded retinas of a 5-day-old air-control dog (A) and a 5-day-old dog after 4 days of hyperoxia (B). The majority of the capillaries have been obliterated. Magnification is $\times 14$. Copyright () 1996 Association for Research in Vision and Ophthalmology. Reproduced from McLeod DS, Brownstein R, Lutty GA. Vasoobliteration in the canine model of oxygen-induced retinopathy. Invest Ophthalmol Vis Sci. 1996;37:300-311.8

Abbreviations: OIR, oxygen-induced retinopathy; ADPase, adenosine diphosphatase.

the dense cellularity of these preretinal formations is apparent. Often adjacent tufts of neovascularization will anastomose with each other forming a vascular complex (Figure 6). Eventually the complexes will anastomose forming a dense matlike structure of new blood vessels, which expands to form an extensive preretinal vascular membrane (Figure 6). ${ }^{12}$ The membranes, when visualized with fundus photography and fluorescein angiography at P22, appear at times to cover an entire vascular arcade (Figure 7). ${ }^{11}$ The preretinal membranes persist at least until P45 (Figure 8) when they appear as tented membranes putting tractional force on the retinas. The result is tractional retinal folds in retina at P45 (Figure 8) similar to those formed in stage IV human ROP.

\section{Anti-VEGF therapy evaluation in the canine OIR model}

In all of the OIR models, VEGF plays a key role in vasculogenic and angiogenic processes in retina. ${ }^{12-14}$ VEGF expression is upregulated in retina during development because there is no retinal vasculature and neurons have become metabolically active, consuming the oxygen that is available. In the dog retina, VEGF receptor-2 (VEGFR2 or kinase domain receptor [KDR]) is present on angioblasts and endothelial cells during development. ${ }^{14}$ However, this receptor is greatly upregulated in vasoproliferative stage of OIR in forming intra-retinal as well as extra-retinal neovascularization (Figure 9). ${ }^{14}$ The effects of neutralization of VEGFR2 in the canine OIR model was evaluated by implanting ELVAX slow-release polymer pellets (Elvax 40; Aldrich Chemical, Milwaukee, WI) with $300 \mu \mathrm{g}$ of antiVEGFR2 (ImClone Systems, New York City, NY, USA) or control non-immune immunoglobulin in the vitreous at P6, 1 day after the removal of the animals from hyperoxia. ${ }^{14}$ The animals were sacrificed at $\mathrm{P} 21$ and vitreous as well as retinas were incubated for ADPase activity. Anti-VEGFR2 inhibited the formation of preretinal neovascularization, which 

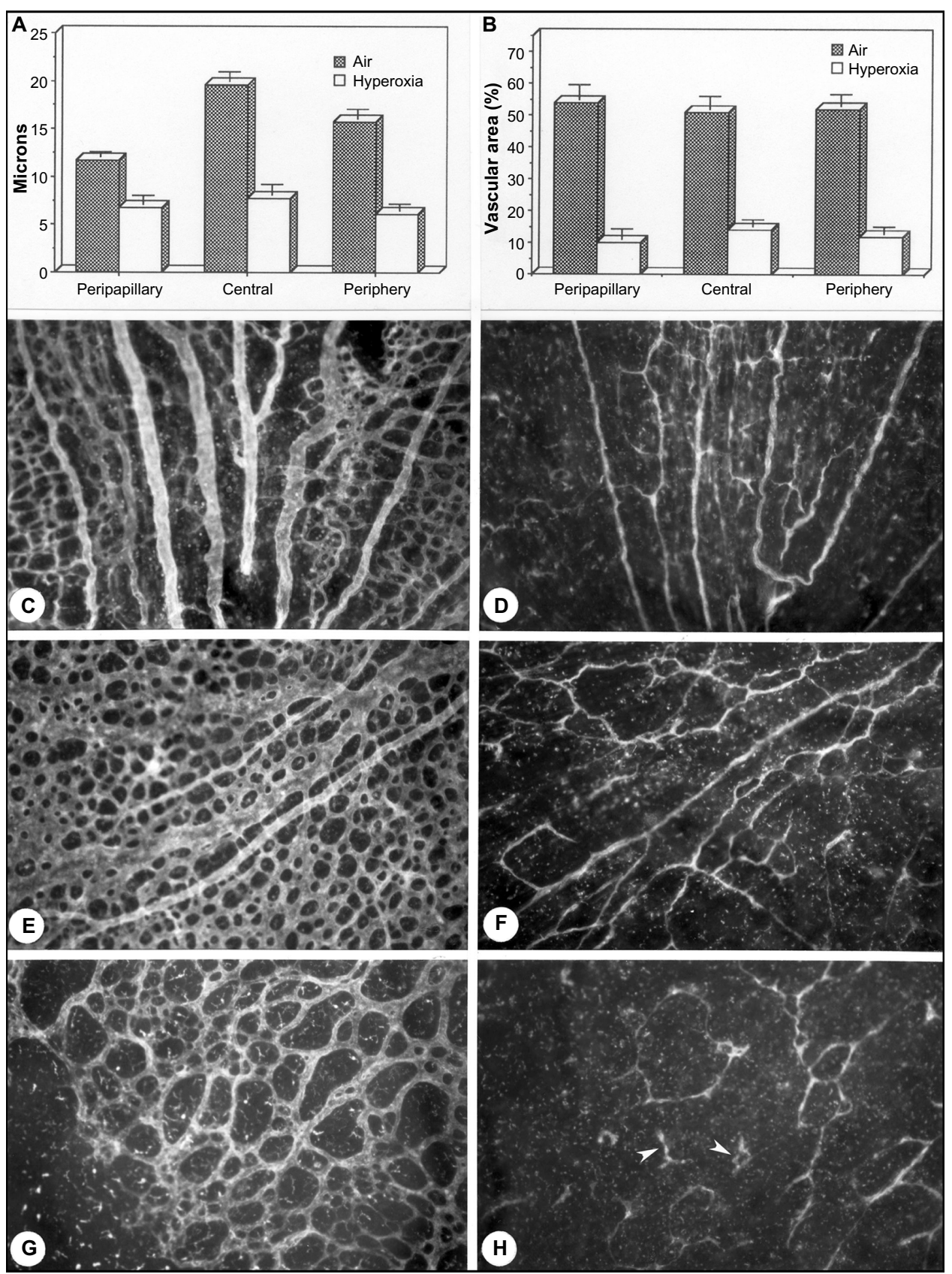

Figure 3 Hyperoxia affects all regions uniformly in the dog OIR model.

Notes: Lumenal diameters (A) and percent vascular area measurements (B) in the peripapillary, midperipheral, and peripheral regions of air controls (C, E, and $\mathbf{G})$ versus oxygen-treated animals (D, F, and H). Arrowheads: surviving vascular endothelial cells and angioblasts. Magnification is $\times 60$. Copyright $\odot 1996$ Association for Research in Vision and Ophthalmology. Reproduced from McLeod DS, Brownstein R, Lutty GA. Vaso-obliteration in the canine model of oxygen-induced retinopathy. Invest Ophthalmol Vis Sci. 1996;37:300-311.8

Abbreviation: OIR, oxygen-induced retinopathy.

remains attached to the vitreous body in dog (Figure 10). ${ }^{14}$ However, anti-VEGFR2 also inhibited the revascularization of retina compared to control $\mathrm{IgG}$, resulting in a reduced retinal vasculature present only in central retina (Figure 10). Analysis of the area of retinal vasculature demonstrated a significant reduction in retinal vasculature in anti-VEGFR2implanted eyes (Figure 11). Similarly, the reduction in the area of neovascularization in vitreous was significant in
anti-VEGFR2 eyes compared to IgG control eyes; therefore, anti-VEGFR2 at the doses used inhibits the formation of preretinal neovascularization as well as revascularization of inner retina.

The effect of VEGF neutralization in canine OIR model was evaluated using the VEGF-Trap (Aflibercept, Regeneron, Tarrytown, NY, USA).The VEGF-Trap is a recombinant fusion protein invented by Regeneron that 

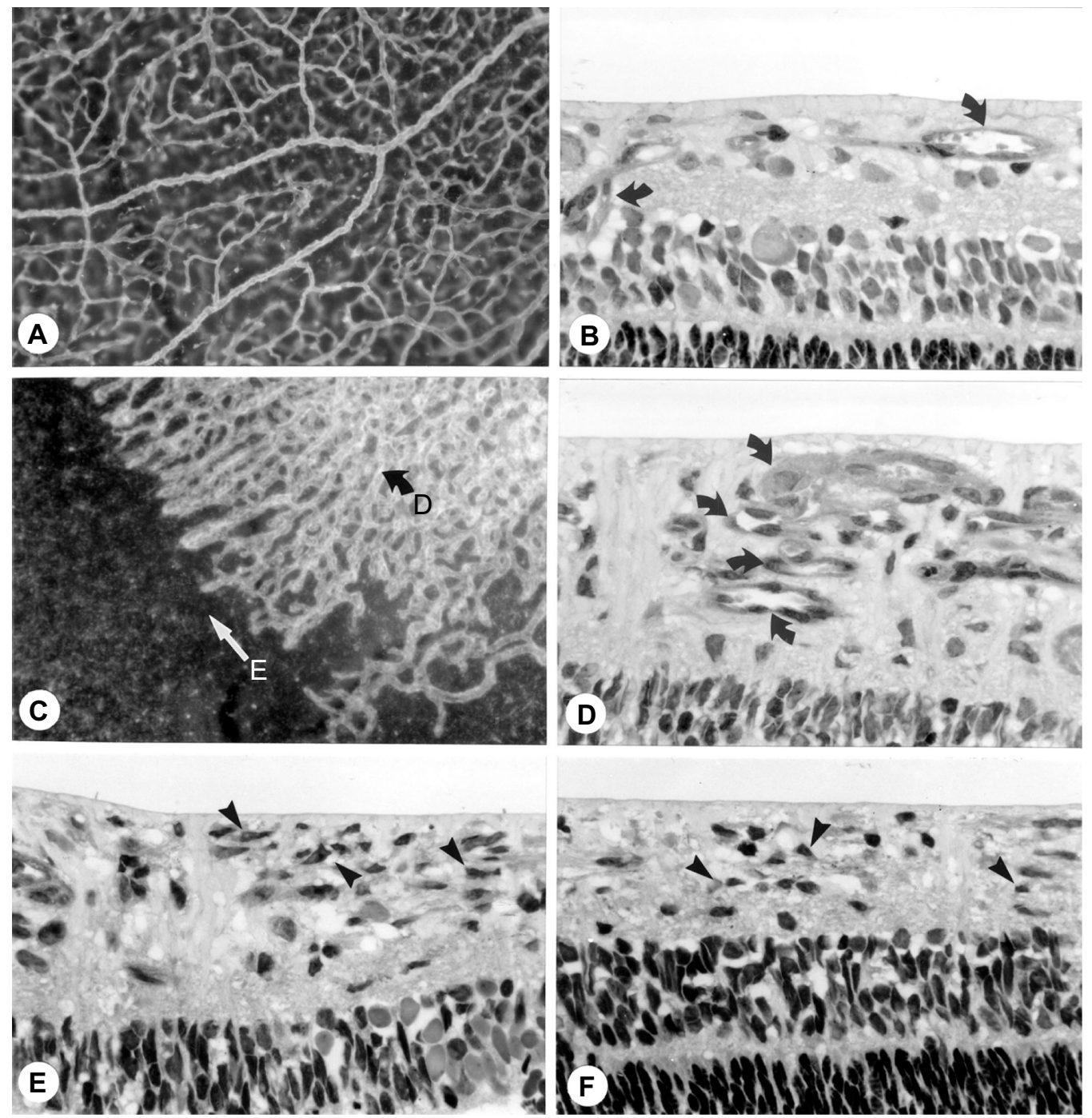

Figure 4 Vasoproliferative phase of OIR in dog.

Notes: Comparison of 22-day-old air control (A and B) and a 22-day-old oxygen-treated animals (C-F) in flat perspective (A and $\mathbf{C})$ and histologic sections (B, D-F). In the air-control animals, inner retinal vasculature is complete and secondary capillaries are formed (curved arrows in $\mathbf{B}$ ). In the oxygen-treated animals, a dense irregular pattern of broad capillaries has formed at the anterior border of revascularized retina (curved arrow in $\mathbf{D}$ ), whereas a substantial area of retina remains avascular (straight arrow in C). Sections taken from the border in the oxygen-treated animal show multiple layers of capillaries at the vascular border (curved arrows in $\mathbf{D}$ ), and numerous astrocytes in advance (arrowheads in $\mathbf{E}$ and $\mathbf{F}$ ), which filled in the extracellular spaces present during normal vasculogenesis. (Magnifications: $A=x 100, B=\times 485, C=x 100, D-F=x 485$ ). Copyright (ㄱ 1996 Association for Research in Vision and Ophthalmology. Reproduced from McLeod DS, Crone SN, Lutty GA. Vasoproliferation in the neonatal dog model of oxygen-induced retinopathy. Invest Ophthalmol Vis Sci. 1996;37:1322-1333. ${ }^{9}$

Abbreviation: OIR, oxygen-induced retinopathy.
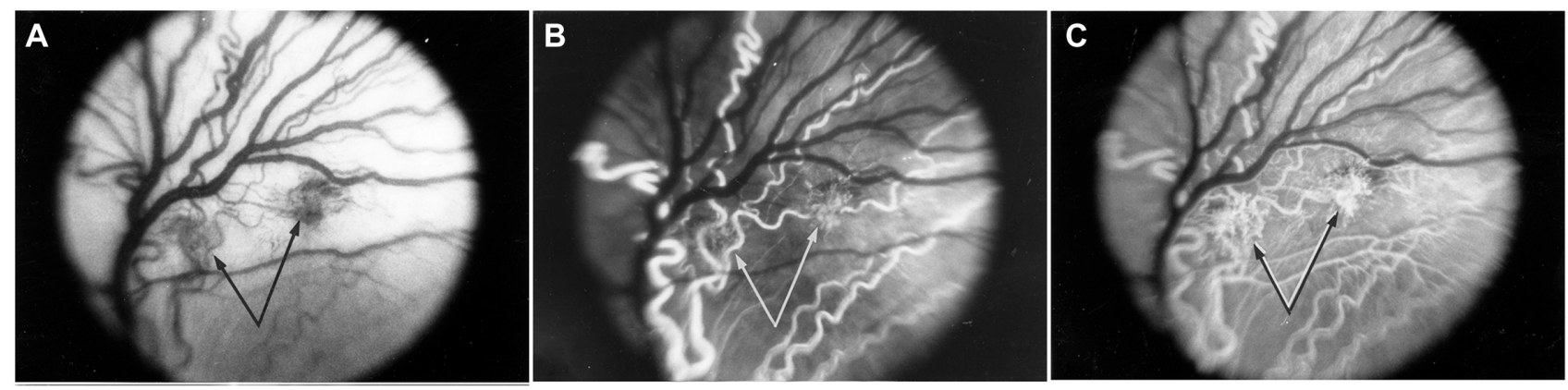

Figure 5 Intravitreal neovascularization in the dog OIR model.

Notes: Red-free photograph (A) and early arterial-phase fluorescein angiogram (B and $\mathbf{C}$ ) showing isolated intravitreal neovascular formations (paired arrows) in the posterior pole of a 45-day-old oxygen-treated animal. These formations are fed by a tortuous retinal artery. Copyright @ 1998 Association for Research in Vision and Ophthalmology. Reproduced from McLeod DS, D'Anna SA, Lutty GA. Clinical and histopathologic features of canine oxygen-induced proliferative retinopathy. Invest Ophthalmol Vis Sci. 1998;39:1918-1932." 


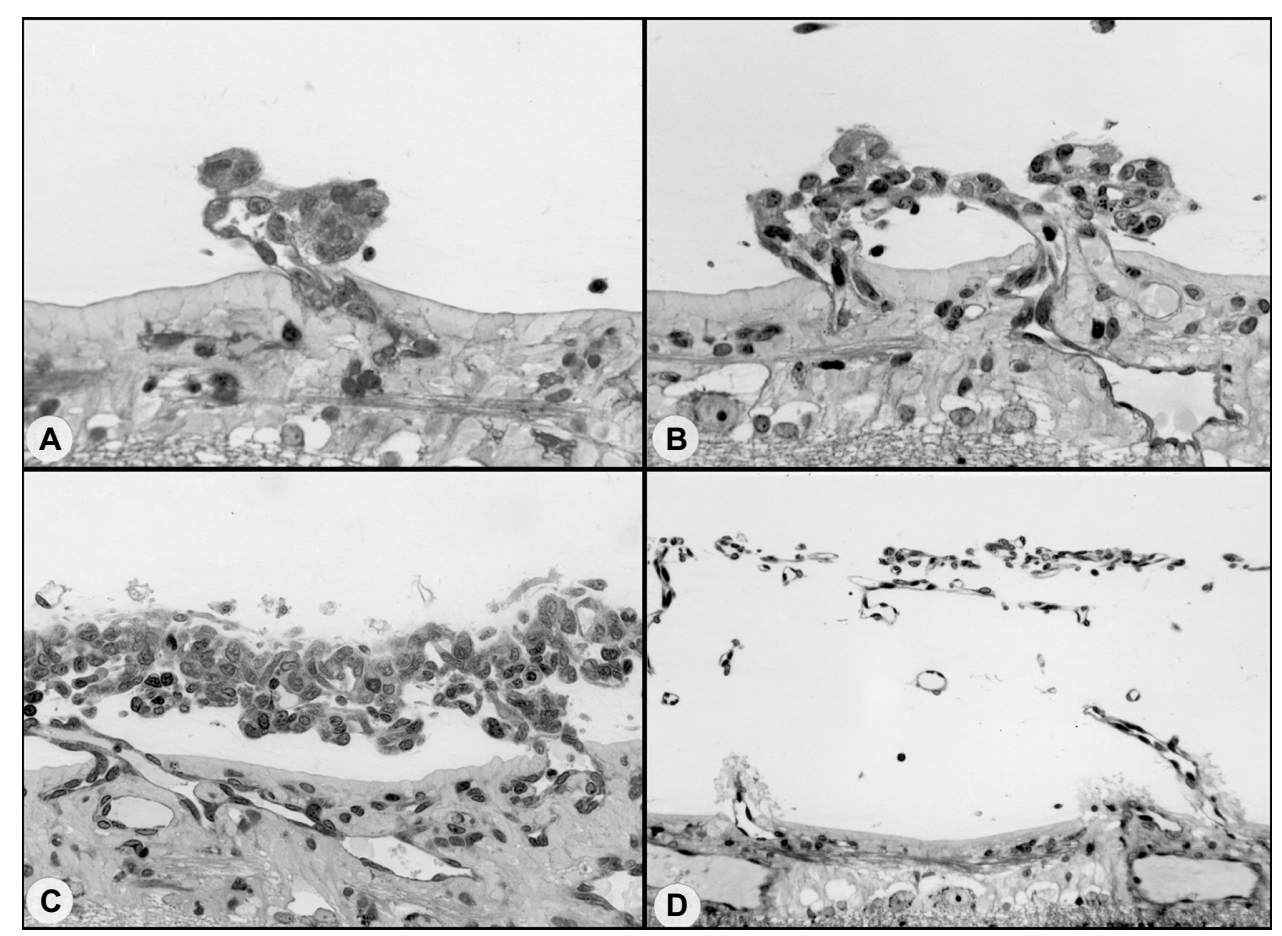

Figure 6 Possible sequence leading to the evolution of inter-anastomosing neovascular networks in the vitreous from a 22-day-old oxygen-treated animal.

Notes: The preretinal neovascular formations in dog could be single isolated polyp-like nodules (A), adjacent nodules with independent feeder vessels apparently anastomosing (B), and formations with increased density of poorly differentiated cellular constituents forming a mat-like structures (C). (D) A network of vessels with well-differentiated cellular components and perivascular collagen elevated above the retinal surface. Magnifications: $A$ and $B=\times 400, C=\times 300$, $D=\times 200$. Copyright $($ ) I998 Association for Research in Vision and Ophthalmology. Reproduced from McLeod DS, D'Anna SA, Lutty GA. Clinical and histopathologic features of canine oxygen-induced proliferative retinopathy. Invest Ophthalmol Vis Sci. 1998;39:1918-1932."
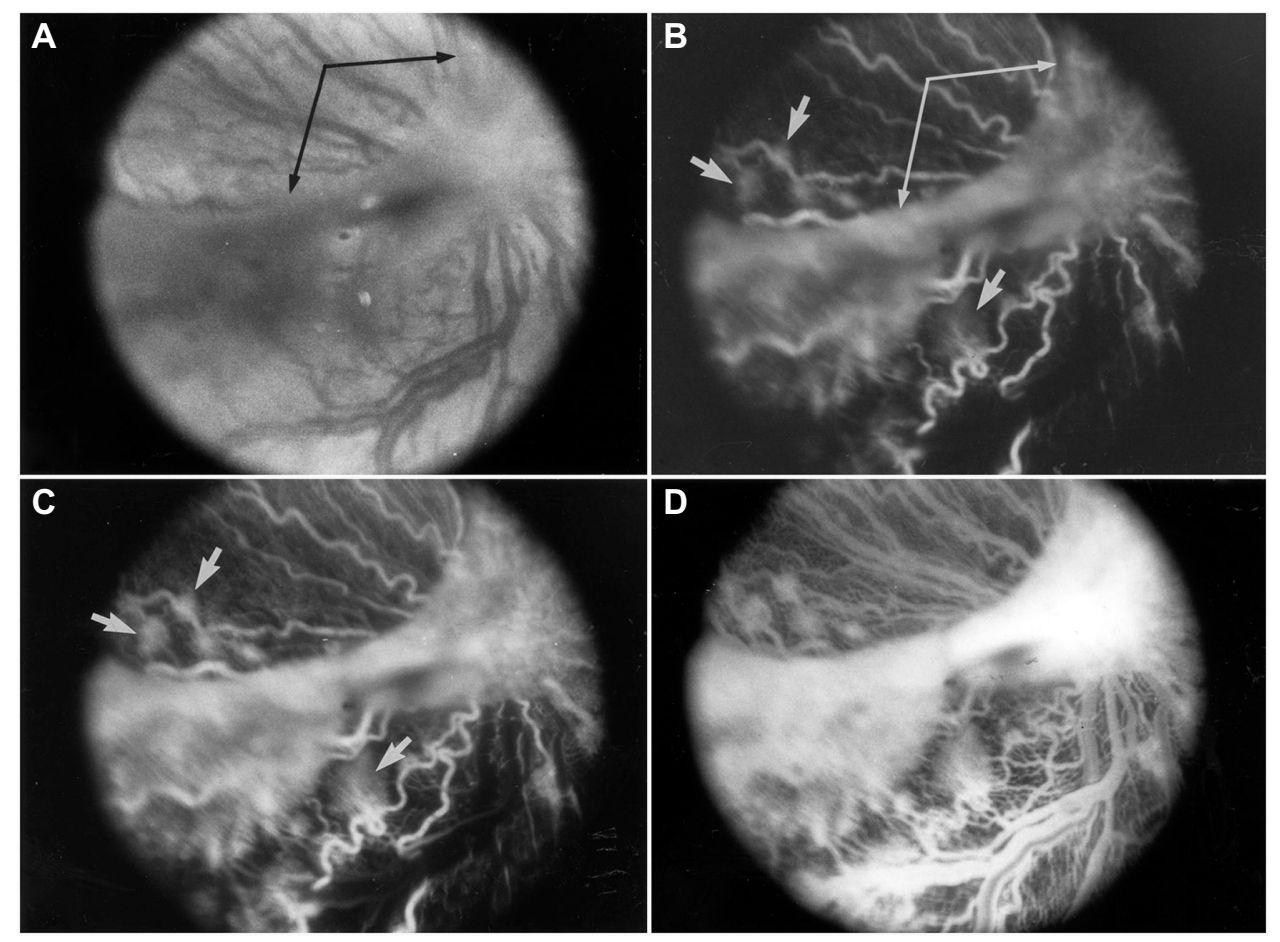

Figure 7 Clinical appearance of vascularized membranes in oxygen-treated animals.

Notes: Red-free fundus photograph (A) and fluorescein angiogram (B-D) showing a vascularized membrane that extends peripherally from the optic disk along the temporal vascular arcade from the optic disc (paired arrows in $\mathbf{A}$ and $\mathbf{B}$ ) and fills during the arterial phase of the angiogram. Dye readily leaks from the membrane and from isolated neovascular tufts near the edge of the membrane (short arrows in B and C). Copyright (C) 1998 Association for Research in Vision and Ophthalmology. Reproduced from McLeod DS, D'Anna SA, Lutty GA. Clinical and histopathologic features of canine oxygen-induced proliferative retinopathy. Invest Ophthalmol Vis Sci. 1998;39:1918-1932." 


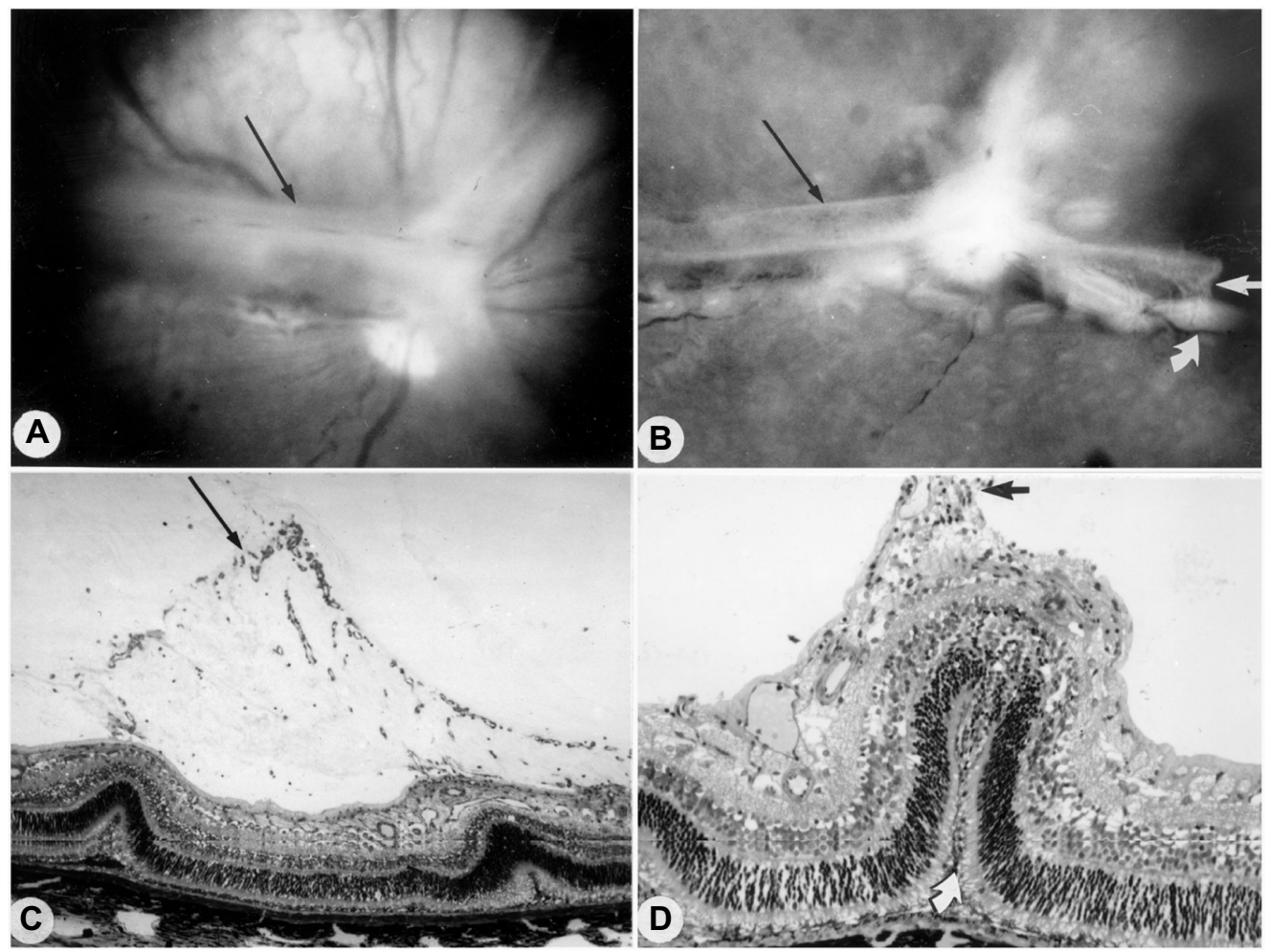

Figure 8 Tented vascularized membrane and tractional retinal folds in a 45-day-old oxygen-treated animal.

Notes: Red-free fundus photograph (A), showing opaque membrane (arrow) extending radially along the major vascular arcades. Gross photograph of the same specimen (B) showing the vascularized membrane (long arrow), tractional retinal attachments to the retina (short arrows), and folding of the retina (arrow). Full-thickness eye-wall sections (C and $\mathbf{D})$ show folding of the retina at the borders of the tented membrane (long arrow) (C) and a full thickness retinal fold (arrows) at the site of traction with the vascularized membrane (D). Magnifications: $C=\times 150, D=\times 125$. Copyright (C) 1998 Association for Research in Vision and Ophthalmology. Reproduced from McLeod DS, D’Anna SA, Lutty GA. Clinical and histopathologic features of canine oxygen-induced proliferative retinopathy. Invest Ophthalmol Vis Sci. 1998;39:1918-1932."

has the binding sites for VEGF-R1 and -R2 fused with the fragment, crystallizable $(\mathrm{Fc})$ portion of human $\mathrm{IgG} 1$. A single 5, 25, or $250 \mu \mathrm{g}$ dose of VEGF-Trap in $50 \mu \mathrm{L}$ was injected into the vitreous at P7. Human Fc at the same doses was injected into control eyes. The effects of these reagents were evaluated at $\mathrm{P} 21$ by incubating both the vitreous and the retina for ADPase activity. All doses of VEGF-Trap resulted in the complete prevention of preretinal neovascularization (Figure 12). ${ }^{16}$ The VEGF-Trap also resulted in smaller areas of retinal vasculature at 25 and $250 \mu \mathrm{g}$ doses (Figure 13); however, the $5 \mu \mathrm{g}$ trap eyes had normal areas of retinal vasculature (Figure 13). The area of retinal vasculature in $5 \mu \mathrm{g}$ dose eyes was comparable to control $\mathrm{Fc}$ injected eyes, so inner retina could revascularize and reduce hypoxia and VEGF production by retina.

\section{Conclusion}

The canine OIR model has many features in common with human ROP. There is profound global vaso-obliteration resulting in the loss of predominantly capillaries and a $50 \%$ reduction in vascular density. The neovascularization is robust in retina and in vitreous. The angiogenesis is so exuberant that large membranes can completely cover the retinal vascular arcades. The model is excellent for evaluating antiangiogenic therapies, including targeting VEGF or its receptor, provided that the reagents recognize dog proteins. The newborn dog eye is comparable in size and its vitreous body is comparable in volume to the premature human eye, so preclinical dosing studies are appropriate in canine OIR. Evaluation of reagents targeting VEGFR2 or VEGF in canine model of OIR demonstrates a very important point: preretinal neovascularization must be inhibited without inhibiting revascularization of retina. Therefore, dosing of the reagents is critical and adult human doses are not appropriate for a premature human eye. ${ }^{17}$ Avery predicted that $6.5 \mu \mathrm{g}$ would seem an appropriate dose for a human premature infant eye, which is almost comparable to our 5 ug dose in the canine OIR model, because the premature human eye is slightly larger than neonatal dog model. The goal is to determine a titer that inhibits preretinal neovascularization but permits revascularization of inner retina. The Japanese gardener's philosophy is excellent guidance in dosing: less is more. 


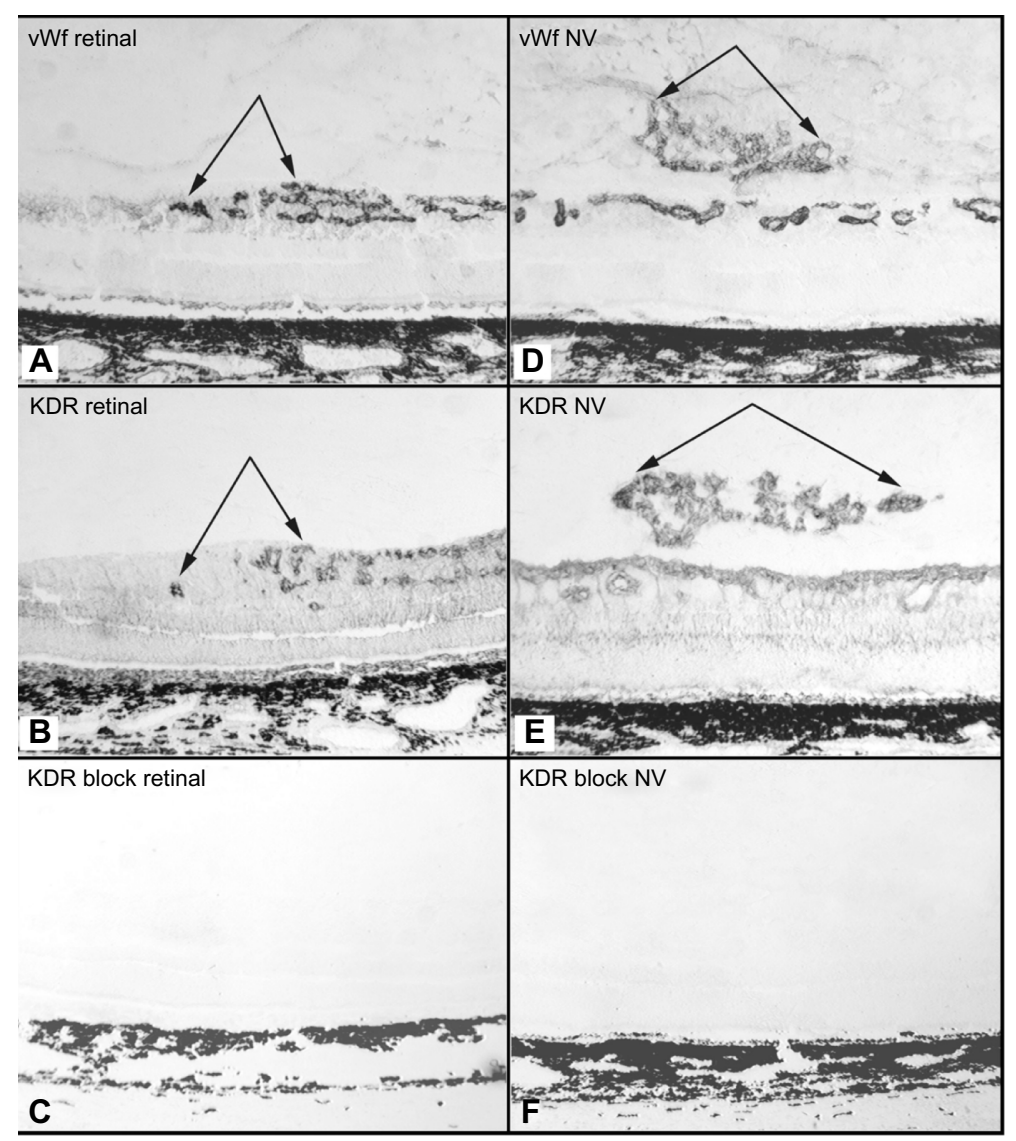

Figure 9 KDR (VEGFR2) localizationin the canine OIR model.

Notes: Sections from a 15-day-old oxygen-treated animal immunostained with anti-vWf (A and D), anti-KDR (VEGFR2) antibody that was preincubated overnight with phosphate buffered saline (B and E), or anti-KDR antibody preincubated overnight with 10 molar excess soluble KDR (sVEGFR2) ( $\mathbf{C}$ and $\mathbf{F}$ ). Shown are the areas from the border of vascularized retina $(\mathbf{A}-\mathbf{C})$ and a more posterior region with intravitreal neovascularization (D-F). Preincubation of antibody with soluble KDR completely eliminated both retinal vascular and intravitreal neovascular immunostaining ( $\mathbf{C}$ and $\mathbf{F})$. Double arrows, amino ethyl carbazol (AEC) reaction product in all; original magnification 50X. Copyright @ 2002 Association for Research in Vision and Ophthalmology. Reproduced from McLeod DS, Taomoto M, Cao J, Zhu Z, Witte L, Lutty GA. Localization of VEGF receptor-2 (KDR/Flk-I) and effects of blocking it in oxygen-induced retinopathy. Invest Ophthalmol Vis Sci. 2002;43:474-482. ${ }^{14}$

Abbreviations: vWf, von Willebrand's factor; KDR, kinase domain receptor; NV, neovascularization.
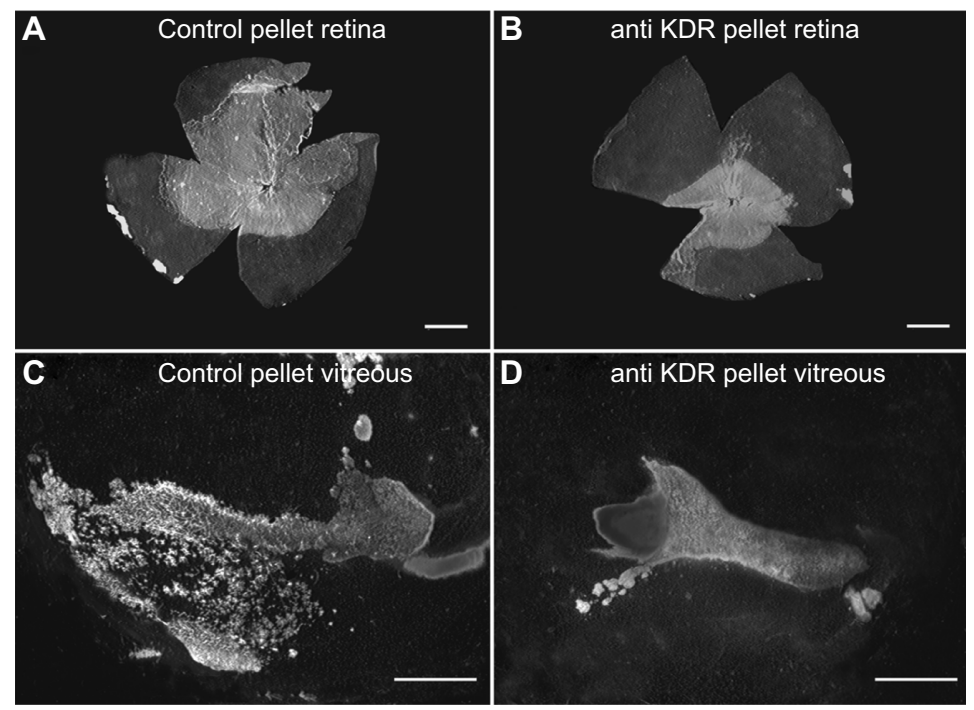

Figure 10 Effect of anti-KDR on dog OIR.

Notes: ADPase-incubated retinas ( $\mathbf{A}$ and $\mathbf{B}$ ) and vitreous bodies ( $\mathbf{C}$ and $\mathbf{D}$ ) from a 22-day-old oxygen-treated animal showing blood vessels (white) in eyes that received a surgically implanted intravitreal control pellet (A and $\mathbf{C}$ ) or an anti-KDR pellet (B and $\mathbf{D})$. Both retinal and intravitreal neovascularization were reduced in the anti-KDR eye. Scale: A and B, $4 \mathrm{~mm}$; C and D 2 mm. Copyright $\odot 1998$ Association for Research in Vision and Ophthalmology. Reproduced from McLeod DS, Taomoto M, Cao J, Zhu Z, Witte L, Lutty GA. Localization of VEGF receptor-2 (KDR/FIk-I) and effects of blocking it in oxygen-induced retinopathy. Invest Ophthalmol Vis Sci. 2002;43:474-482. ${ }^{14}$ Abbreviations: OIR, oxygen-induced retinopathy; ADPase, adenosine diphosphatase; KDR, kinase domain receptor. 

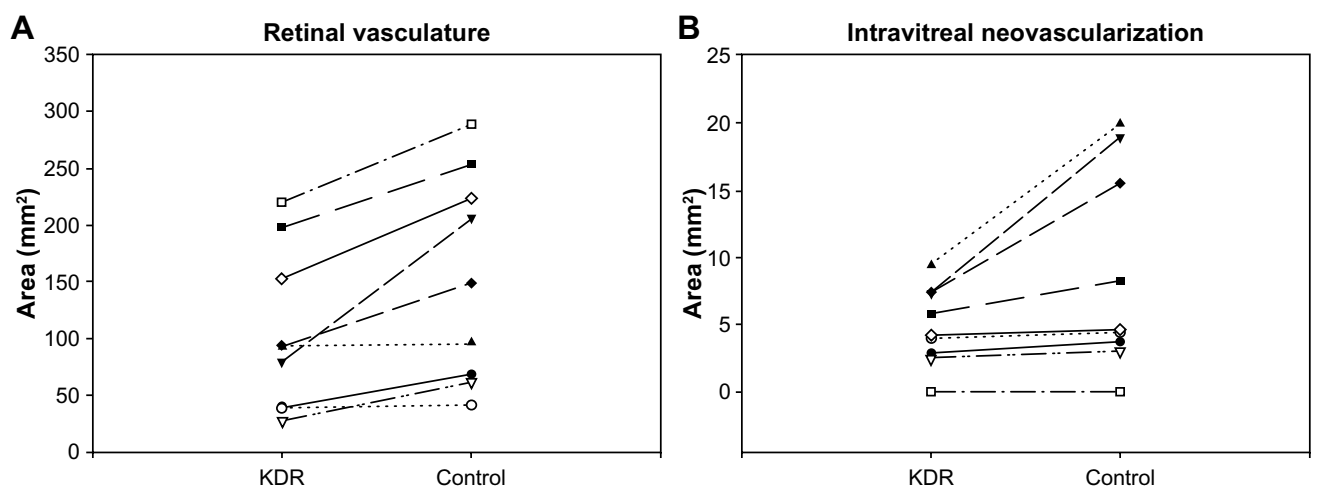

Figure I I Effect of anti-KDR on intravitreal and retinal vascular area.

Notes: Retinal vascular area (A) and intravitreal neovascularization area (B) in a group of oxygen-treated 22-day-old animals that received control pellets in one eye and anti-KDR pellets in the fellow eye. The retinal vascular areas $\left(\mathrm{mm}^{2}\right)$ from paired eyes are shown in $(\mathbf{A})$ and the intravitreal neovascularization areas $\left(\mathrm{mm} \mathrm{m}^{2}\right)$ from paired eyes appear in (B). Wilcoxon matched-pairs signed-ranks test demonstrated that the differences between paired eyes of animals (anti-KDR in one eye and control nonimmune immunoglobulin in the fellow eye) in retinal vascular areas $(P=0.0039)$ and in intravitreal neovascularization areas $(P=0.0078)$ were significant. Copyright $(C)$ I998 Association for Research in Vision and Ophthalmology. Reproduced from McLeod DS, Taomoto M, Cao J, Zhu Z, Witte L, Lutty GA. Localization of VEGF receptor-2 (KDR/FIk-I) and effects of blocking it in oxygen-induced retinopathy. Invest Ophthalmol Vis Sci. 2002;43:474-482.14 Abbreviation: KDR, kinase domain receptor.
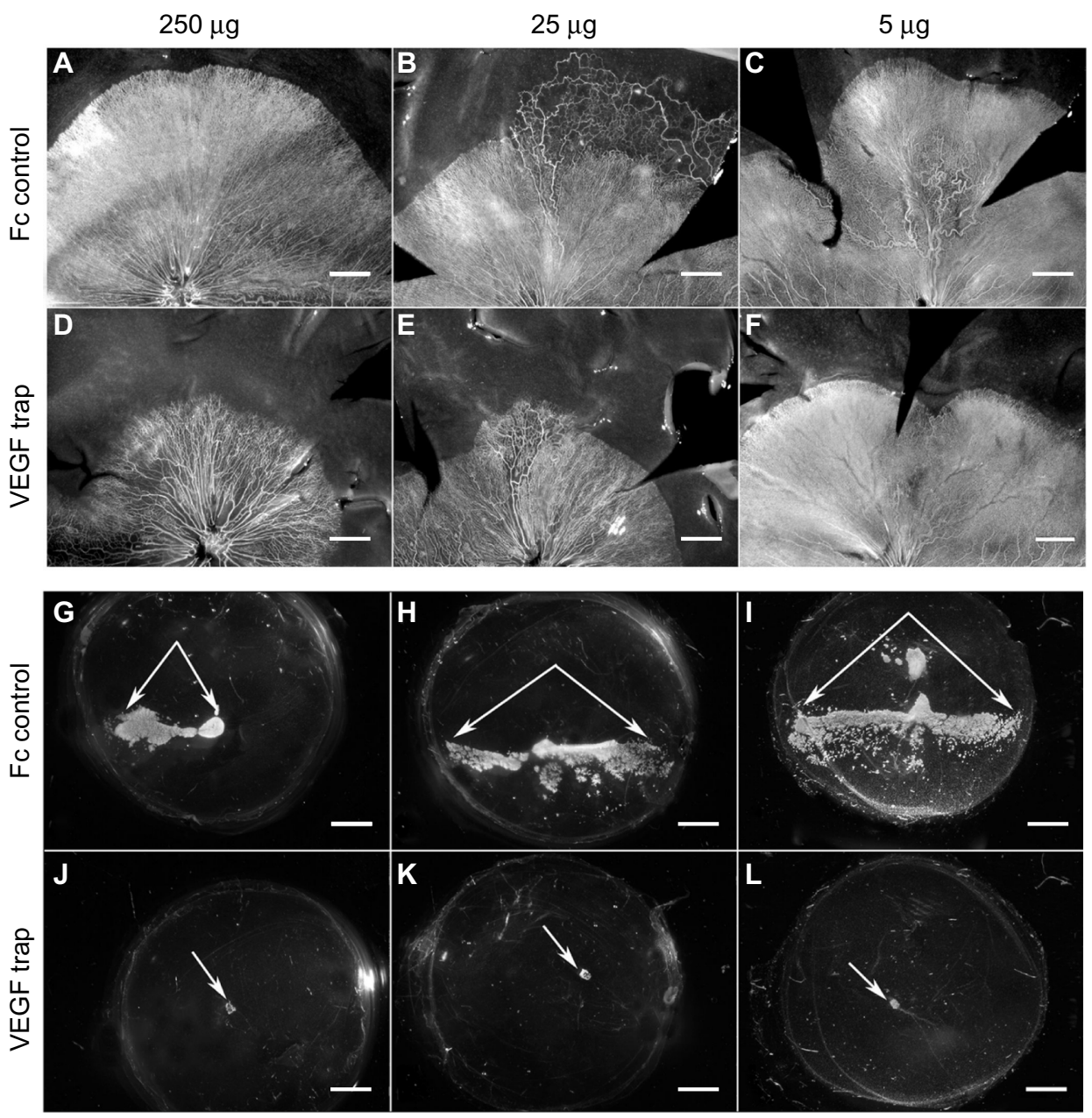

Figure 12 Retinal vasculature and intravitreal neovascularization after treatment with VEGF-Trap.

Notes: ADPase-incubated retinas $(\mathbf{A}-\mathbf{F})$ and vitreous bodies $(\mathbf{G}-\mathbf{L})$ from postnatal day 2 I oxygen-exposed dogs that were treated with human fraction crystallizable (Fc) or VEGF-Trap. The 250 and $25 \mu \mathrm{g}$ doses of VEGF-Trap inhibited centripetal growth of retinal blood vessels toward ora serrata in a dose-dependent manner (D-E) compared to the hFc-treated eyes (A-B). In contrast, the retinal vascular area in oxygen-exposed eyes treated with $5 \mu \mathrm{g}$ VEGF-Trap (F) was greater than in the human Fc-injected control eyes (C). ADPase-incubated vitreous bodies from the hFc injected eyes had considerable intravitreal neovascularization (paired arrows in $\mathbf{G}-\mathbf{I}$ ) while the vitreous bodies from VEGF-Trap-treated eyes had no appreciable ADPase-positive vitreous neovascularization (NV) at all doses tested (arrows=optic nerve head in J-L). Scale bars: A-F= Imm; G-L=2mm. Copyright (C) 20I I Association for Research in Vision and Ophthalmology. Reproduced from Lutty GA, McLeod DS, Bhutto I, Wiegand SJ. Effect of VEGF trap on normal retinal vascular development and oxygen-induced retinopathy in the dog. Invest Ophthalmol Vis Sci. 20I I;52:4039-4047. ${ }^{16}$

Abbreviation: ADPase, adenosine diphosphatase. 
A

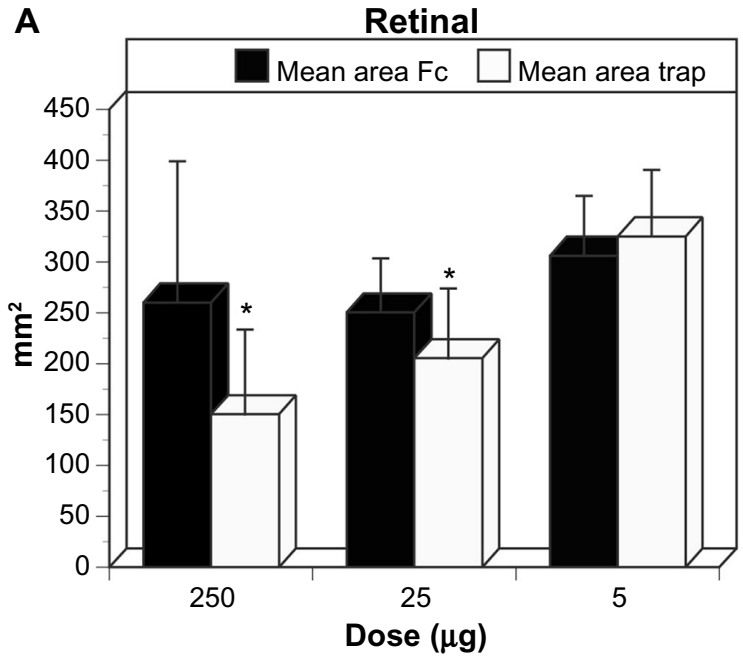

B

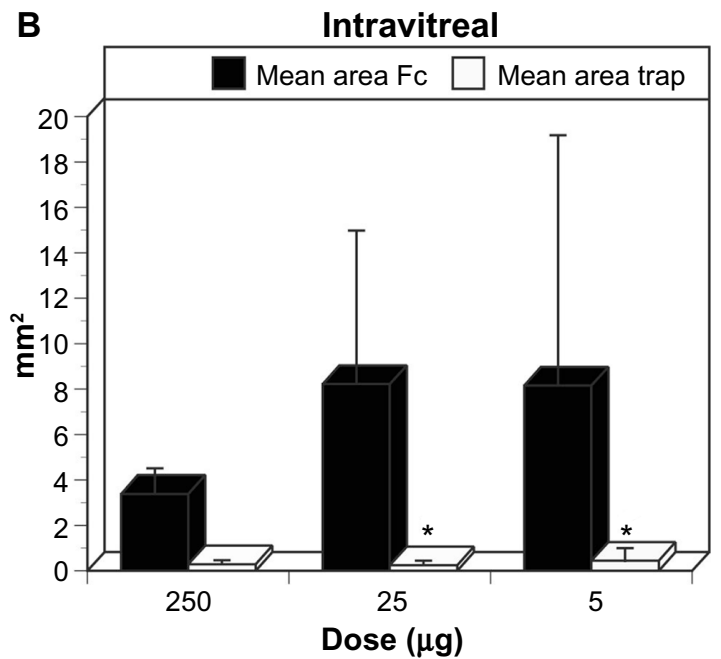

Figure 13 Retinal and intravitreal vasculature areas after treatment with VEGF-Trap

Notes: $(\mathbf{A})$ The mean retinal vascular areas $( \pm$ SD) of post natal day 21 oxygen-exposed animals were the smallest in the 25 and $250 \mu g$ trap-treated eyes compared to human fraction crystallizable $(\mathrm{Fc})$-injected eyes $(* P<0.05$, Tukey's honest significant difference test). The overall effect of treatment on retinal vascular area was statistically significant by ANOVA $(F, 7.953 ; P=0.032)$, as was the treatment $\times$ dose interaction $(F, 5.14 ; P=0.037)$. There was no difference in retinal vascular area between $\mathrm{h} F \mathrm{c}$ control eyes and eyes that received $5 \mu \mathrm{g}$ VEGF-Trap. (B) The mean area of intravitreal NV was reduced significantly in all animals treated with 25 and $5 \mu \mathrm{g}$ VEGF-Trap compared to human $\mathrm{Fc}\left({ }^{*} P<0.05\right.$; Tukey's test). The overall effect of treatment on vitreal $N V$ also was statistically significant by $A N O V A(F, 6.696 ; P=0.032)$. Although intravitreal $N V$ was suppressed to an equivalent extent in the $250 \mu \mathrm{g}$ dose group, this was not statistically significant due to the lower level of NV observed in the fellow eyes treated with $250 \mu \mathrm{g} \mathrm{hFc}$. Copyright (C) $201 \mathrm{I}$ Association for Research in Vision and Ophthalmology. Reproduced from Lutty GA, McLeod DS, Bhutto I, Wiegand SJ. Effect of VEGF trap on normal retinal vascular development and oxygen-induced retinopathy in the dog. Invest Ophthalmol Vis Sci. 201 I;52:4039-4047.'6

Abbreviation: NV, neovascularization.

\section{Acknowledgments}

This study was supported by NIH grants RO1-EY09357 (GAL) and EY001765 (Wilmer Ophthalmological Institute CORE grant) and unrestricted funds from Research to Prevent Blindness (unrestricted funds to Wilmer). The Johns Hopkins School of Medicine Institutional Animal Care and Use Committee provided Ethics approval and also approved the use of dogs for this study in accordance with the guidelines of the Association for Research in Vision and Ophthalmology on use of laboratory animals.

\section{Disclosure}

The authors report no other conflict of interest in this work.

\section{References}

1. Patz A, Eastham A, Higgenbotham D, Kleh T. Oxygen studies in retrolental fibroplasia: II. the production of the microscopic changes of retrolental fibroplasia in experimental animals. Am J Ophthalmol. 1953;36:1511-1522.

2. Kimura T, Chen CH, Patz A. Light and electron microscopic studies of intravitreal proliferative tissues in human and puppy eyes. Nippon Ganka Gakkai Zasshi. 1979;83:255-265.

3. Flower RW, Blake DA, Wajer SD, Egner PG, McLeod DS, Pitts SM. Retrolental fibroplasia: evidence for a role of the prostaglandin cascade in the pathogenesis of oxygen-induced retinopathy in the newborn beagle. Ped Res. 1981;15:1293-1302. 1. Hasegawa T, McLeod DS, Prow T, Merges $\mathrm{C}$, Grebe R, Lutty GA. Vascular precursors in developing human retina. Invest Ophthalmol Vis Sci. 2008;49:2178-2192.

4. McLeod DS, Lutty GA, Wajer SD, Flower RW. Visualization of a developing vasculature. Microvasc Res. 1987;33:257-269.

5. McLeod DS, Hasegawa T, Prow T, Merges C, Lutty G. The initial fetal human retinal vasculature develops by vasculogenesis. Dev Dyn. 2006;235:3336-3347.
6. Chan-Ling T, McLeod DS, Hughes S, et al. Astrocyte-endothelial cell relationships during human retinal vascular development. Invest Ophthalmol Vis Sci. 2004;45:2020-2032.

7. McLeod DS, Merges C, Selden SC, Lutty GA. Histochemical localization of $5^{\prime}$ nucleotidase and adenosine in the normal and oxygen exposed neonatal beagle retina. Invest Ophthalmol Vis Sci. 1992;33:1085.

8. McLeod DS, Brownstein R, Lutty GA. Vaso-obliteration in the canine model of oxygen-induced retinopathy. Invest Ophthalmol Vis Sci. 1996;37:300-311.

9. McLeod DS, Crone SN, Lutty GA. Vasoproliferation in the neonatal dog model of oxygen-induced retinopathy. Invest Ophthalmol Vis Sci. 1996;37:1322-1333.

10. Lutty GA, McLeod DS. Increased retinal glial expression of GFAP and $5^{\prime}$ nucleotidase in response to hyperoxia. Invest Opthalmol Vis Sci. 1987;28:204.

11. McLeod DS, D'Anna SA, Lutty GA. Clinical and histopathologic features of canine oxygen-induced proliferative retinopathy. Invest Ophthalmol Vis Sci. 1998;39:1918-1932.

12. Baba T, McLeod DM, Edwards MM, et al. VEGF ${ }_{165} \mathrm{~b}$ in the developing vasculatures of the fetal human eye. Dev Dyn. 2012;241: 595-607.

13. Lutty GA, McLeod DS. Retinal vascular development and oxygeninduced retinopathy: a role for adenosine. Prog Ret Eye Res. 2003;22:95-111.

14. McLeod DS, Taomoto M, Cao J, Zhu Z, Witte L, Lutty GA. Localization of VEGF receptor-2 (KDR/Flk-1) and effects of blocking it in oxygeninduced retinopathy. Invest Ophthalmol Vis Sci. 2002;43:474-482.

15. Murata T, Nakagawa K, Khalil A, Ishibashi T, Inomata H, Sueishi K. The temporal and spatial vascular endothelial growth factor expression in retinal vasculogenesis of rat neonates. Lab Invest. 1996; 74:68-77.

16. Lutty GA, McLeod DS, Bhutto I, Wiegand SJ. Effect of VEGF trap on normal retinal vascular development and oxygen-induced retinopathy in the dog. Invest Ophthalmol Vis Sci. 2011;52:4039-4047.

17. Avery RL. Bevacizumab (Avastin) for retinopathy of prematurity: wrong dose, wrong drug, or both? JAAPOS. 2012;16:2-4. 
Eye and Brain

\section{Publish your work in this journal}

Eye and Brain is an international, peer-reviewed, open access journal focusing on clinical and experimental research in the field of neuroophthalmology. All aspects of patient care are addressed within the journal as well as basic research. Papers covering original research, basic science, clinical and epidemiological studies, reviews and evaluations,

Submit your manuscript here: http://www.dovepress.com/eye-and-brain-journal

\section{Dovepress}

guidelines, expert opinion and commentary, case reports and extended reports are welcome. The manuscript management system is completely online and includes a very quick and fair peer-review system, which is all easy to use. Visit http://www.dovepress.com/testimonials.php to read real quotes from published authors. 